\title{
RANCANG BANGUN MEJA DAN KURSI BELAJAR SECARA ERGONOMI DIBENGKEL LAS NUANSA TEKNIK LUBUK BUAYA PADANG
}

\author{
Tri Ernita ${ }^{1}$ Irawanto $^{2}$ \\ ${ }^{1}$ Program Studi Teknik Industri, Sekolah Tinggi Teknologi Industri Padang \\ Email: triernita@sttind.co.id
}

\begin{abstract}
ABSTRAK: Meja belajar dan kursi merupakan alat pendukung yang sangat penting dalam pelaksanaan pengajaran dan pembelajaran. Untuk mengantisipasi adanya ketidaksesuaian antara meja dan kursi dengan ukuran tubuh siswa, maka pembuatan meja dan kursi belajar harus dirancang secara ergonomis sesuai dengan ukuran tubuh manusia. Maka tujuan dari penelitian ini adalah untuk merancang desain meja dan kursi secara ergonomis dan mengetahui biaya yang dikeluarkan untuk membuat meja ergonomis dan pembelajaran kursi. Hasil dari penelitian ini adalah meja belajar baru dan kursi yang terbuat dari pipa besi dan memiliki lebar dudukan $37 \mathrm{~cm}$, tinggi dudukan $39 \mathrm{~cm}$, tinggi jok keseluruhan $90 \mathrm{~cm}$, tinggi jok $43 \mathrm{~cm}$, jok keseluruhan $74 \mathrm{~cm}$, lebar meja $55 \times 42 \mathrm{~cm}$, rak buku $39 \times 37 \mathrm{~cm}$, rak buku setinggi $16 \mathrm{~cm}$, tumpuan kaki $13 \times 37 \mathrm{~cm}$, pijakan tinggi $23 \mathrm{~cm}$, sandaran busa dan penahan $7 \mathrm{~cm}$. Adapun total biaya pembuatan meja dan kursi belajar hasil akhir ini adalah Rp. $815.500,-$.
\end{abstract}

Kata kunci: Antrhophometry, Ergonomi, Desain.

ABSTRACT: Study tables and chairs are very important supporting tools in the implementation of teaching and learning. To anticipate the discrepancy between tables and chairs and the size of the student's body, the making of study tables and chairs must be ergonomically designed according to the size of the human body. So the purpose of this research is to design ergonomic design of tables and chairs and find out the costs incurred to make ergonomic tables and chair learning. The results of this study are new study tables and chairs made of iron pipes and has a seat width of $37 \mathrm{~cm}$, seat height of $39 \mathrm{~cm}$, overall seat height of $90 \mathrm{~cm}$, upholstery height of $43 \mathrm{~cm}$, overall seat $74 \mathrm{~cm}$, table width $55 \times 42 \mathrm{~cm}$, bookshelf $39 \times 37 \mathrm{~cm}$, bookshelves as high as $16 \mathrm{~cm}$, foot support $13 \times 37 \mathrm{~cm}, 23 \mathrm{~cm}$ high footing, foam backrest and $7 \mathrm{~cm}$ support. The total cost of making study tables and chairs this final result is $R p .815,500$.

Keywords: Anthropometry, Ergonomics, Design.

\section{PENDAHULUAN}

Kenyamanan dalam sebuah aktifitas adalah sebuah kebutuhan mutlak yang sangat dicari dan dioptimalkan oleh setiap creator maupun inovator di bidang human comfortable. Berbagai macam bentuk model perlindungan maupun peralatan yang menunjang sebuah nilai keamanan pada diri manusia, seperti halnya pakaian yang melindungi manusia dari kondisi alam di sekitar tubuh yang dibalutnya, dan sudah tentu hal ini membutuhkan campur tangan seorang designer sebagai pencipta sekaligus pemberi nilai lebih dibidang estetika dan daya persuasive. Kursi dan meja merupakan salah satu faktor yang paling berhubungan erat dalam meningkatkan kualitasbelajar.Apabila kursi dan meja yang dipakai kurang ergonomis maka, pada saat dilaksanakannya proses belajar mengajar mahasiswa akan merasa lelah dan tidak fokus terhadap apa yang dipelajarinya. Maka dengan demkianpenulis akan pembuat rancang bangun meja dan kursi 
belajar yang nantinya diharapkan bisa memberikan kenyamanan saat proses belajar mengajar.

Selain sebagai meja belajar, meja ini juga bisa digunakan untuk meja laptop karena meja ini dirancang bisa dimiringkan sesuai dengan kebutuhan masing-masing mahasiswa.

Menurut Manuaba (2000), istilah ergonomi didefenisikan sebagai suatu upaya dalam bentuk ilmu teknologi dan seni untuk menyerasikan peralatan, mesin, pekerjaan, sistem, organisasi, lingkungan, dengan kemampuan, keahlian manusia sehingga tercapai suatu kondisi dan lingkungan yang sehat, aman, efisien dan produktif, melalui pemanfaatan fungsional tubuhmanusia secara optimal dan maksimal.

\section{METODE PENELITIAN}

Adapun jenis penelitian yang digunakan adalah penelitian eksperimen perancangan, yakni suatu rancangan percobaan dengan setiap langkah tindakan yang betul-betul terdefenisikan sedemikian rupa sehingga informasi yang berhubungan dengan atau diperlukan untuk persoalan yang sedang diteliti dapat dikumpulkan.

Selain itu desain experimen didefenisikan sebagai suatu pengujian atau serangkaian pengujian yang bertujuan untuk melakukan perubahan terhadap variabel-variabel input dari proses atau sistem sehingga dapat meneliti dan mengidentifikasi sebab-sabab perubahan dari output (Sumadi, 1998).

\section{HASIL DAN PEMBAHASAN AnalisaPengukuran Bahan}

Bahan baku yang diperlukan dalam pembuatan mejadankursi ini adalah :

1. Pengkuranpipa $3 / 4$ inci diameter $3 \mathrm{~cm}$ denganukuran $43 \mathrm{~cm}$ untukpembuatan kaki kursi.

2. Pengkuranpipa $3 / 4$ inci diameter $3 \mathrm{~cm}$ denganukuran 42 $\mathrm{cm}$ untukpembuatantinggisandaranpunggu ng.
3. Pengkuranpipa $3 / 4$ inci diameter $3 \mathrm{~cm}$ denganukuran 37

$\mathrm{cm}$ untukpembuatanlebarsandaranpunggu ng.

4. Pengkuranpipa $3 / 4$ inci diameter $3 \mathrm{~cm}$ $\begin{array}{llll}\text { denganukuran39 } & \text { x } & 37 & \mathrm{~cm}\end{array}$ untukpembuatandudukankursi.

5. Memotongpipa $3 / 4$ incidenganukuran 43 $\mathrm{cm}, 42 \mathrm{~cm}, 37 \mathrm{~cm}, 39 \times 37 \mathrm{~cm}$

6. Perakitanataupengelasan pipa $3 / 4$ incidenganukuran $42 \mathrm{c}, \mathrm{mcm}, 37 \mathrm{~cm}$, $39 \times 37 \mathrm{~cm}$ dan pipa1/2denganukuran $73 \mathrm{~cm}$ untukpembuatan kaki meja, 33 cm untukpembuatandudukanmeja.

7. Penggerindaan pipa yang telah di las.

8. Pengukuran besi beton diameter $6 \mathrm{~mm}$ dengan ukuran $39 \mathrm{~cm} \times 37 \mathrm{~cm}$.

9. Pengelasan besi beton diameter $6 \mathrm{~mm}$ dengan ukuran $39 \mathrm{~cm} \mathrm{x} 37 \mathrm{~cm}$.

10. Penggerindaan besi beton yang telah di las.

11. Pengukuran besi plat tebal $0,2 \mathrm{~mm}$ untutempat pijakan kaki dengan ukuran $13 \mathrm{~cm}$ x $37 \mathrm{~cm}$.

12. Pengelasan pijakan kaki dengan ukuran $13 \mathrm{~cm}$ x $37 \mathrm{~cm}$.

13. Penggerindaan pijakan kaki yang tela di las.

14. Pengukuran papan trilpek dengan ukuran $55 \mathrm{~cm}$ x 42 cmuntukmeja, 39 cm x 37 cmuntuk alas dudukan, $42 \mathrm{~cm}$ x 37 cmuntukpembuatansandaran.

15. Pemotongan papan trilpek dengan ukuran $55 \mathrm{~cm}$ x 42 cmuntukmeja, 39 cm x 37 cmuntuk alas dudukan, $42 \mathrm{~cm}$ x 37 cmuntukpembuatansandaran.

16. Pengeboran, pembersihan dan pembentukan papan trilpek yang telah di potong.

17. Mengukur busa tempat duduk dan sandaran punggung dengan ukuran 39 cm x 37 cmuntukdudukan, $42 \mathrm{~cm}$ x 37 cmuntuksandaranpunggung.

18. Memotong busa dengan ukuran $39 \mathrm{~cm}$ x $37 \mathrm{~cm}, 42 \mathrm{cmx} 32 \mathrm{~cm}$.

19. Pengukuran kain jok kursi dengan ukuran $49 \mathrm{~cm}$ x $47 \mathrm{~cm}, 52 \mathrm{~cm}$ x $42 \mathrm{~cm}$.

20. Pemotongan kain jok dengan ukuran $49 \mathrm{~cm} \times 47 \mathrm{~cm}, 52 \mathrm{~cm}$ x $42 \mathrm{~cm}$. 
21. Pemasangan kain jok dengan ukuran $49 \mathrm{~cm} \mathrm{x} 47 \mathrm{~cm}, 52 \mathrm{~cm} \mathrm{x} 42 \mathrm{~cm}$.

22. Finising.

\section{AnalisaWaktuPengerjaan}

Waktu pengerjaan dalam pembuatan mejadankursibelajar ini dimulai dari proses pengukuran dan pemotongan bahan, penggerindaan,pengelasan,perakitan/assem bling, hingga finishing diperkirakan lebih kurang sekitar 1440 menit/3 hari jam kerja untuk menyelesaikan mejadankursibelajar ini.

\section{AnalisaBiaya}

Adapun biaya pembuatan meja dan kursi belajar iniyang harus dikeluarkan agar meja dan kursi belajar ini bisa diproduksi. Berikut adalah biaya yang dikeluarkan untuk pembuatan meja dan kursi belajar yang baru :
a. Besipipahitam 3 bh $=$ Rp.121.000
b. Kawatlas NK $1 \mathrm{~kg}=\mathrm{Rp} \cdot 20.000$
c. Dempul besi $1 \mathrm{bh}=\mathrm{Rp} .18 .000$
d. Cat kaleng $\quad 1 b h=R p .49 .000$
e. kain amplas $\quad 1 \mathrm{bh}=\mathrm{Rp} .10 .000$
f. Busa
2.bh= Rp. 100.000
g. Kain jok
$1 / \mathrm{m}=\mathrm{Rp} .30 .0000$
h. Batu Gerinda $\quad 1 \mathrm{bh}=\mathrm{RP} .8000$
i. $\quad$ Baut $10 \quad 8$ bh $=$ Rp. 8000
j. $\quad$ Baut 12
$6 \mathrm{bh}=\mathrm{Rp} .10 .500$
k. Cat pernis
$1 \mathrm{bh}=\mathrm{Rp} .56 .000$
1. Besi beton 6
$1 \mathrm{~m}=$ Rp. 25.000
m. Papan trilpek 1mtr= Rp.45.000
n. Sewa peralatan Las $=$ Rp.315.000

\section{Total Biaya Alat dan Bahan}

Jadi total biaya keseluruhan untuk pembuatan seperator hasil akhir mejadankursibelajariniadalah Rp.815.500.

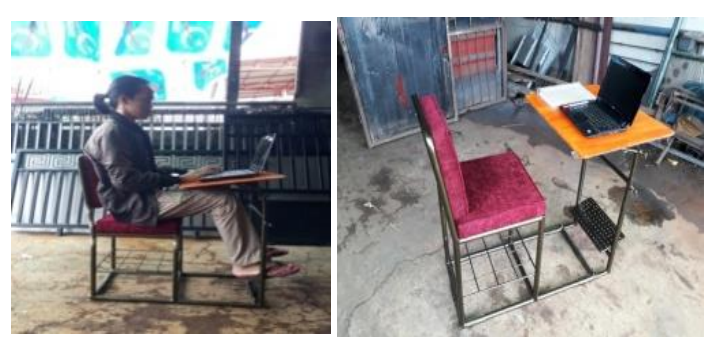

Gambar 1. Teknik Rancang Bangun Meja dan Kursi Belajar.
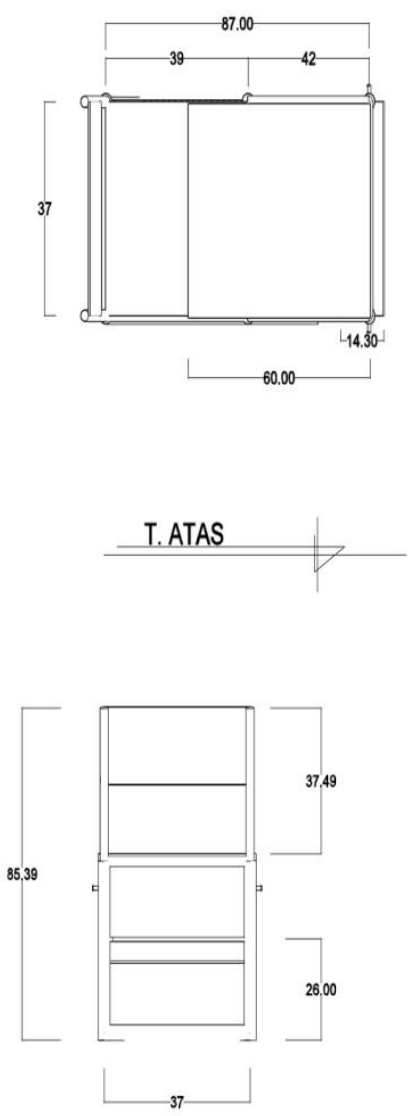

T.DEPAN

\section{HasilAkhir}

Hasil Uji Coba

Hasil akhir meja dan Kursi Belajar. 

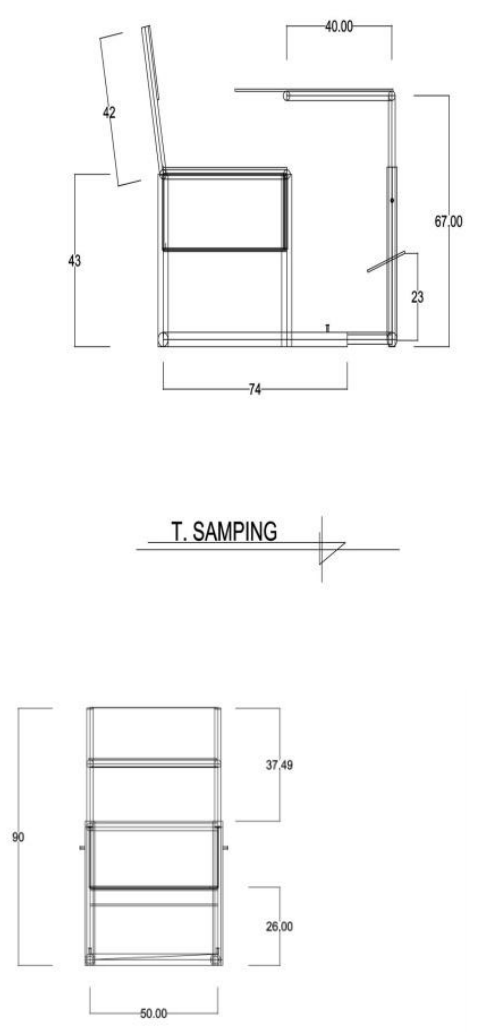

T. BELAKANG

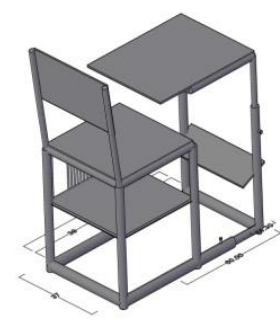

Gambar 2. Perspektif

\section{KESIMPULAN}

Setelah melakukan penelitian, membuat alat serta melakukan uji coba, maka dapat disimpulkan bahwa perancangan dan pembuatan mejadan kursi belajar ini adalah sebagai berikut :

1. Meja dan kursi belajar yang dirancang sekarang sudah sangat nyaman.

2. Meja dan kursi belajar yang dirancang sekarang sudah sangat membantu proses belajar mengajar.
Adapun saran yang akan diberikan adalah sebagai berikut :

1. Ada baiknya rancangan meja dan kursi belajar yang sekarang ini bisa diproduksi lebih banyak lagi.

2. Rancangbangun meja dan kursi belajar ini masih belum sempurna dan peneliti menyarankan agar penelitian ini bisa lebih disempurnakan lagi.

\section{DAFTAR PUSTAKA}

Eppinger, Steven D. Metode Perancangan dan Pengembangan Produk. Edisi Pertama. Salemba Teknika, Jakarta. 2001.

Indrawan Nugroho. Rancang Bangun Meja Multifungsi Dengan Munggunakan Metode Rasional (Jurnal).Universitas Dian Nuswantoro, Semarang. 2004.

Jugianto, Andi Offset. Analisis Perancangan dan Desain. Universitas Gajah Mada, Yogyakarta. 1991.

Manuaba. Ergonomi Dalam Industri. Universitas Udayana, Bali. 2000.

Nurmantio, Eko. Ergonomi Konsep Dasar dan Aplikasinya. Guna Widya.Edisi Kedua. Surabaya. 2004.

Sevilla et AL. Metode Pengambilan Sampel. Universitas Indonesia. Jakarta. 1960.

Sumadi. Metodologi Penelitian. Raja Grafindo Persada, Jakarta. 1998.

Umar.Populasi dan Sampel.PT. Gramedia Pustaka Utama, Jakarta. 1997.

Wignjosoebroto. Ergonomi, Studi Gerak dan Waktu, Teknik Analisis UntukPeningkatan Produktifitas Kerja. Edisi Pertama. Jakarta. 2000. 